\title{
DisCURSO, HistóRIA E FORMAS DE ConstituiçÃo Do "EU" FEMININo EM AnTigos AnÚNCIOS DE MEDICAMENTOS
}

\section{Discourse history and forms of constituition of feminine in old medicine announcements}

\author{
Nincia Borges Teixeira* \\ Denise Gabriel Witzel ${ }^{* *}$
}

"Tão longe quanto se possa olhar no horizonte da história, vê-se apenas a dominação masculina”, escreveu Michelle Perrot (2005, p. 468). A partir dessa afirmação, pretendemos voltar nosso olhar para o passado dos anúncios publicitários, para um momento sócio-histórico que propiciou a aparição dos primeiros discursos publicitários impressos e verificar, em tais discursos, os modos de subjetivação do feminino a partir da análise de elementos que compunham o cotidiano das mulheres nas primeiras décadas do século XX. Para isso, filiamo-nos ao campo da Análise do Discurso, derivada de Michel Pêcheux.

Nosso interesse em melhor compreender o funcionamento da linguagem publicitária de outrora advém do fato de que, ao enunciar o feminino no bojo de uma sociedade marcada pelos valores da cultura patriarcal, produzem-se efeitos de sentidos que, de um lado, possibilitamnos compreender a construção de alguns discursos fundadores (ORLANDI, 1993) dos discursos (re)produzidos na atualidade; de outro, oferece importantes elementos linguísticos e discursivos que nos permitem analisar os vestígios que atravessam e constituem os movimentos identitários da mulher no percurso de sua história no Brasil.

* Professora Adjunta de Literatura Brasileira, Departamento de Letras da Unicentro. Pós-Doutora em Ciência da Literatura.

* Professora Assistente do Departamento de Letras da Unicentro. Doutoranda em letras - Unesp (Araraquara). 
Assim, selecionamos de um corpus constituído por inúmeros anúncios que marcaram fortemente a propaganda daquela época, 4 peças publicitárias que falam diretamente às mulheres. São exemplares que, além de orientar sobre o alcance e o poder terapêutico do medicamento anunciado, reproduzem e sustentam práticas identitárias mediante o uso de uma linguagem (verbal e não verbal) altamente sedutora e, não raro, amedrontadora. Ao reverberar as condutas e as maneiras de ser/viver desejadas para o público visado, a propaganda pretende conquistar possíveis compradores, mas a adesão somente ocorre se houver uma identificação com os valores culturais trabalhados no interior do anúncio. Há uma incessante busca e uma troca com um interlocutor/consumidor cúmplice, próximo. É, pois, o funcionamento discursivo dessas peças publicitárias e as imagens que dali emergem que nos interessam e, para analisá-las, focalizamos a relação entre discurso e prática identitária.

\section{Discurso PublicitáRIo e As REPRESENTAÇõEs DE GÊNERO}

A língua, entendida pelo viés discursivo, não é transparente; tampouco pode ser pensada isoladamente. A ideia de que há, de um lado, uma "evidência", uma "verdade" e uma "realidade" na produção de sentidos e, de outro, um sujeito fundador, origem daquilo que diz, é uma ilusão, pois a produção de sentidos ocorre em função da articulação entre a língua e o discurso, e dessa relação participam, de forma constitutiva, os elementos sócio-históricos, a exterioridade. Isso torna impossível pensar que os sentidos possam ser literais, ou mesmo que possam ser qualquer um, já que a materialidade só produz sentido(s) porque está enraizada na história e resulta de práticas sociais. São, portanto, as condições de produção que regem a interpretação de qualquer discurso.

O indivíduo, na esteira do pensamento pecheutiano, é interpelado em sujeito pela ideologia, pelo simbólico na história. Orlandi $(2006$, p.19) explica essa noção com as seguintes palavras:

A interpelação do indivíduo em sujeito de seu discurso se efetua pela identificação do sujeito com a formação discursiva que o domina. [...] essa identificação, fundadora da unidade imaginária do sujeito, apóia-se no fato de que os elementos do interdiscurso que constituem, no discurso do sujeito, os traços daquilo que o determina, são re-escritos no discurso do próprio sujeito.

Ao considerar o discurso como o lugar de contato entre a língua e a ideologia, uma vez que a materialidade ideológica se concretiza no discurso, Pêcheux (1997) postula que os efeitos de sentido de um discurso dependem 
da formação ideológica a partir da qual o discurso é produzido. Isso porque o sentido de determinadas palavras depende dessas posições ideológicas, dos lugares sociais dos sujeitos que as empregam.

As formações discursivas, por sua vez, "são a projeção, na linguagem, das formações ideológicas", conforme Orlandi (2006, p. 17). Pêcheux (1997, p. 166) argumenta que as formações discursivas, inscritas em determinadas formações ideológicas, "determinam o que pode e deve ser dito a partir de uma posição dada numa conjuntura, isto é, numa certa relação de lugares no interior de um aparelho ideológico [...]”. Nesse sentido, ao se considerar as formações discursivas de um discurso, considera-se também que o funcionamento do discurso acontece a partir de certa regularidade, o que torna possível compreender o processo de produção dos sentidos e a sua relação com a ideologia.

É necessário ainda acrescentar que os discursos, que são produzidos no interior das formações discursivas, estão constantemente dialogando com outros discursos produzidos em outras formações discursivas, fazendo surgir daí o interdiscurso. Isso significa que todo discurso é considerado uma dispersão de textos porque se relaciona com outros discursos e os sentidos procedem dessas relações. É um estado de um processo discursivo mais amplo, contínuo, não possuindo nem início nem ponto final, pois se apoia em já-ditos, que o sustentam, e se remete para outros futuros. A interdiscursividade nos permite verificar, por exemplo, que todo e qualquer discurso sempre nasce de um trabalho sobre outros discursos, frente aos quais é uma resposta direta ou indireta, ou sobre os quais ele 'orquestra' os termos principais, ou cujos argumentos destrói, conforme postulou Pêcheux (1997).

Em suma, uma formação discursiva representa o lugar de articulação entre o discurso e a língua, sendo constitutivamente 'invadida' por pré-construídos que são justamente os elementos produzidos em outro(s) discurso(s), anteriores ao discurso em estudo, independentemente dele. É, pois, como ensinou Foucault (1997): uma formação discursiva relaciona um sistema de dispersão.

Essa rápida e preliminar incursão por alguns conceitos-chave da Análise do Discurso nos instiga a questionar o funcionamento discursivo dos anúncios publicitários, atentando para a inscrição do dizer em uma dada formação discursiva e os efeitos de sentido a partir do entendimento de que as peças publicitárias, que compõem nosso corpus de análise, podem ser tomadas como um lugar da memória, cuja rede simbólica que as envolve entrelaça e emaranha discursos de determinada época e cultura, o que, no nosso entendimento, contribui na formação de identidades. 
Partimos do princípio de que os textos publicitários constituem-se numa unidade de significação que somente podem ser analisados e interpretados se for considerada a natureza sincrética desse tipo de texto em relação à situação discursiva e ao conjunto de discursos possíveis que fazem emergirem as significações, a partir de mitos, crenças e ideologias que povoavam o imaginário coletivo da época em que tais discursos circularam. Em se tratando especificamente das peças selecionadas, vale esclarecer que elas se destinavam a um público feminino bem definido: eram especialmente as mulheres burguesas, de classe privilegiada e urbana, que eram interpeladas pelas propagandas dos medicamentos anunciados.

Direcionaremos nossas análises considerando, igualmente, que o desenvolvimento dos papéis de gênero e a formação de identidades são discursivamente construídos e aprendidos nas relações históricas, sociais e culturais nas quais o sujeito se inscreve desde seu nascimento. É, portanto, na dinâmica das relações sociais que se começa a perceber a diferença entre o feminino e o masculino. A noção de gênero é entendida aqui como relações estabelecidas a partir da percepção social das diferenças biológicas entre os sexos (SCOTT, 1995). Foucault (1999) afirma que aquele que lê (uma obra de arte, um livro, um filme, uma fotografia, uma história em quadrinhos) entra na cena e ao construí-la é construído, é subjetivado pelos discursos que no texto operam e, neste mesmo jogo, posicionado como sujeito. A leitura do texto vai constituindo uma leitura dos objetos, dos acontecimentos, das coisas descritas - no roteiro, no cenário, na história -, e está ancorada em discursos tidos como verdadeiros num tempo, num contexto, numa cultura. A linguagem constrói "realidades", sujeitos, posições a serem ocupadas, instituindo oposições binárias.

Essa percepção, por sua vez, está baseada em esquemas que opõem masculino/feminino, sendo esta oposição homóloga e relacionada a outras: forte/fraco; grande/pequeno; acima/abaixo; dominante/dominado (BOURDIEU, 1999). Os discursos que fomentam tais oposições/ hierarquizações são arbitrários e, como já dissemos, historicamente construídos.

A publicidade sempre se apresentou como espaço onde trafegam discursos que sedimentam valores e ideologias de determinada época. Assim, por ser um campo fértil em que são cultivadas as representações que os homens devem construir sobre o mundo, o discurso publicitário dos antigos anúncios de medicamentos se realizava na medida em que dialogava com as representações que se estabeleciam de acordo com o modo de significação da ideologia da época, sobretudo a que reproduzia os valores burgueses, estabelecendo sua legitimidade de publicação e fixando certos padrões de pensamento e comportamento. 
Com efeito, as produções discursivas abaixo (Figuras 1 e 2), ao falarem diretamente à figura feminina, reiteravam certas crenças difundidas no imaginário social, especialmente com relação à premissa de que a mulher seria um ser doente. E era com essa imagem coletiva que a consumidora, em sua existência particular, deveria se identificar.

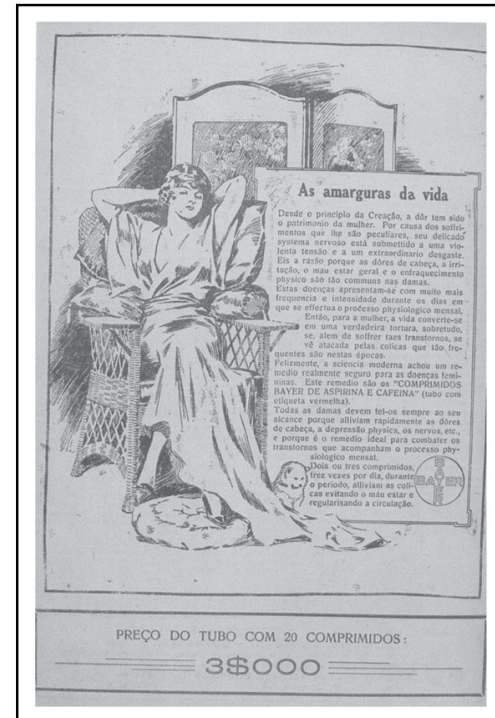

\section{As armaguras da vida}

Desde o princípio da Creação, a dôr tem sido o patrimônio da mulher. Por causa dos sofrimentos que lhe são peculiares, seu delicado systema nervoso está submetido a uma violenta tensão e a um extraordinário desgaste. Eis a razão porque as dôres de cabeça, a irritação, o mau estar geral e o enfraquecimento physico são tão communs nas damas.

Essas doenças apresentam-se com muito mais freqüência e intensidade durante os dias em que se effectua o processo physiológico mensal.

Então, para a mulher, a vida converte-se em uma verdadeira tortura, sobretudo, se, além de sofrer taes transtornos, se vê atacada pelas cólicas que tão freqüentes são nestas épocas.

Felizmente, a sciência moderna achou um remédio realmente seguro para as doenças femininas. [...]

Todas as damas devem tel-os sempre ao seu alcance porque alliviam rapidamente as dôres de cabeça, a depressão physica, os nervos, etc., e porque é o remédio ideal para combater os transtornos que acompanham o processo physiologico mensal.

Dois ou tres comprimidos tres vezes por dia, durante o período, alliviam as collicas evitando o mau estar e regularisando a circulação.

FIGURA 1- RECLAMES DA BAYER 1911-1942 (p. 48).

A constituição do 'eu' feminino em evidência nesse anúncio, veiculado na Revista Careta de Janeiro de 1921, apresenta a mulher como debilitada, adoentada e nervosa, principalmente durante o período menstrual. As doenças femininas - dores de cabeça, irritação, mau estar geral e enfraquecimento físico - associadas à predisposição para as dores, já que os sofrimentos lhe são peculiares, além de seu delicado sistema nervoso submetido a uma violenta tensão e a um extraordinário desgaste, em suas diferentes formas de dizer, (re)afirmam o mesmo: a mulher seria o sexo frágil, ao que fazem eco os discursos imemoriais de dominação, em cujo cerne fixou-se a ideia de que a mulher estaria ligada à natureza e o homem, à cultura.

A interdiscursividade, como dito anteriormente, é constitutiva de todo e qualquer discurso, uma vez que "algo fala (ça parle) sempre antes, 
em outro lugar independentemente" (PÊCHEUX, 1995, p. 162). Podemos verificar um diálogo interdiscursivo entre o discurso da propaganda acima e o discurso bíblico, já que, na bíblia, Deus expulsa Eva do paraíso dizendolhe: "Tu darás à luz na dor", o que tornou a dor o patrimônio da mulher. Segundo Perrot (2007, p. 75), "essa maldição bíblica" foi fatal, pois o sofrimento passou a ser considerado como algo inevitável e constitutivo da identidade do feminino.

Foucault (apud PERROT, 2005, p. 497), ao interrogar-se sobre a medicalização do corpo feminino e sobre o fato de que, durante muito tempo, tentou-se ligar o feminino à sua sexualidade, mostra que a mulher sempre foi confundida com seu próprio sexo; este, além de frágil, seria quase sempre doente e indutor de doenças, exatamente como foi representado na propaganda acima. $O$ alvo da medicalização era o útero, ainda conforme Foucault, pois todo drama feminino, em sua prática cotidiana, estaria associado à sua anatomia, ao fato de que esse órgão seria o responsável pelas amarguras de sua vida e isso, certamente, faz emergir a memória da mulher histérica ${ }^{1}$.

Entendendo que as diferenças biológicas entre o corpo masculino e o feminino são construídas como justificativas naturais para as diferenças sociais entre os gêneros, Bourdieu (1999), por sua vez, afirma que a definição social dos órgãos sexuais é produto não do registro de propriedades naturais expostas à percepção, mas do processo de acentuação de certas diferenças e obscurecimento de semelhanças.

Assim, legitima-se um discurso de dominação a partir da inscrição em formações discursivas que sustentam sentidos sobre a natureza biológica. Aos olhos da propaganda, todo o drama feminino derivaria do fato de que ela é vista como mais fraca, mais delicada, mais sensível, sempre a exigir, portanto, a proteção masculina do pai/marido, atingindo a leitora em seu mundo de relações. $O$ anúncio se apresenta como paradigma social que comunica experiências, modos de comportamento e normas do bem viver em permanente intercâmbio com os meios sociais com os quais interage e dialoga. Nesse discurso, a representação da figura feminina transparece sob a forma de uma imagem na qual se evidencia um sistema de valores e comportamento socialmente atribuídos, ou seja, uma imagem que, segundo Gastaldo (2005, p. 60), "fica no lugar do grupo".

\footnotetext{
${ }^{1}$ A histeria, durante muito tempo, foi vista como uma doença associada à fragilidade e às carências exclusivamente femininas. A etimologia da palavra histeria esclarece essa crença, pois sua origem vem da palavra grega hystera, que significa útero. Acreditava-se que era dele que migrava o sangue contaminado que, chegando ao cérebro, levaria às convulsões (PERROT, 2007). Muitas mulheres do século XIX, diagnotiscadas como histéricas, foram encerradas nos mesmos asilos e manicômios que os epilépticos e os doentes mentais.
} 


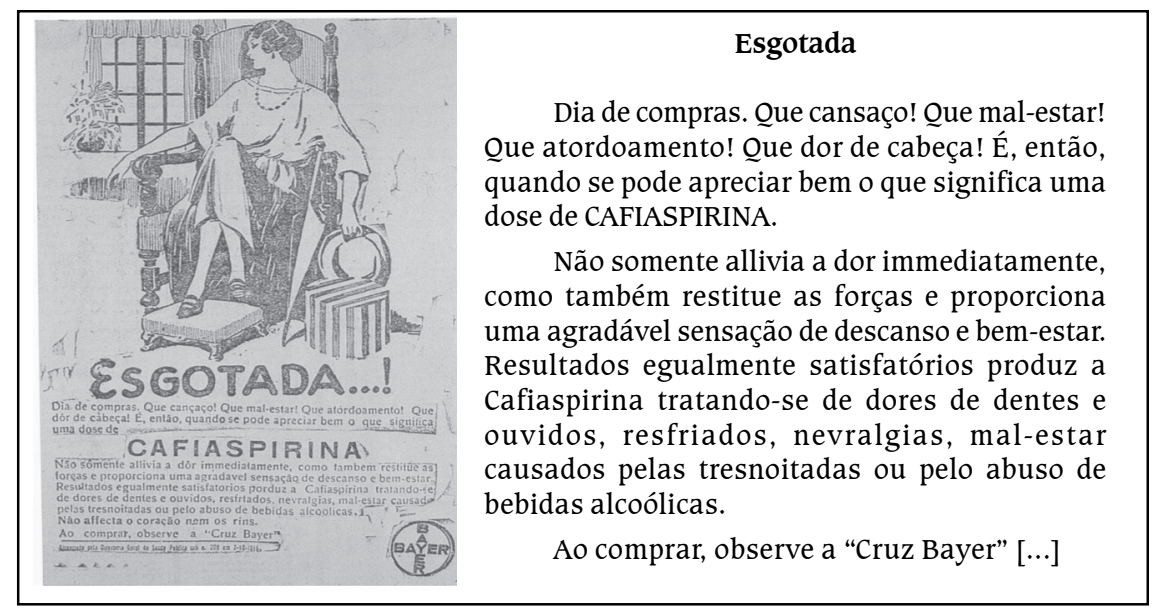

FIGURA 2 - RECLAMES DA BAYER 1911-1942 (p. 61).

Nesse outro anúncio, publicado no Estado de São Paulo em março de 1925 , vemos novamente a mulher desfalecida sobre uma poltrona, com evidentes sinais de cansaço e desânimo após uma fatigante jornada de compras. Para muitas mulheres dessa época, sobretudo na cultura burguesa, as compras figuravam como importante parte de seu papel social, pois em suas práticas cotidianas, a elas cabia a responsabilidade de conduzir e de manter o bom funcionamento doméstico.

Sobre o perfil "exemplar" da mulher burguesa dessa época, vale lembrarmos que ela deveria possuir "bons hábitos de economia e de higiene, valores morais de pudor, obediência, polidez, renúncia, sacrifício" (PERROT, 2007 , p. 93). Todos esses ingredientes, ao mesmo tempo em que teciam a coroa das virtudes femininas, possibilitavam-lhe desempenhar seu principal papel: o de dona de casa. Na materialidade discursiva do anúncio, vemos a configuração dessa idealização, ou seja, a propaganda sugere que a mulher atente para sua frágil constituição física e psíquica de modo a eliminar quaisquer desequilíbrios, mentais ou físicos, que porventura possam interferir negativamente no desempenho de seus afazeres domésticos. Nessa, e em muitas outras propagandas, o discurso médico é mobilizado para dar a medida exata daquilo que se entendia ser a vocação feminina.

É importante notar que o mundo interno, representado no anúncio, ao expressar o sofrimento - esgotada - e a individualidade feminina, passa a ser a representação coletiva que assume lugar de fato social. A identidade da mulher não é a dimensão do indivíduo; ela tem seu registro na classificação coletiva e se constitui através de valores também sociais investidos nesses espaços. No mundo dentro do anúncio, tal como nos é transmitido rotineiramente, encena-se uma vida parecida com a real, cotidiana, idêntica. Sendo assim, vemos a representação da figura que se encaixa em estereótipos como submissa, frágil, sobrecarregada, a exemplo do anúncio anterior (Figura 1). 
Goffman (apud GASTALDO, 2005) já observara que muitos anúncios evocam a divisão e a hierarquia tradicional entre os sexos. Não raro, as mulheres aparecem em posições subalternas ou de assistentes. Já os homens, em posição mais alta, simbolizando um estatuto superior. É o que podemos constatar nos anúncios a seguir:

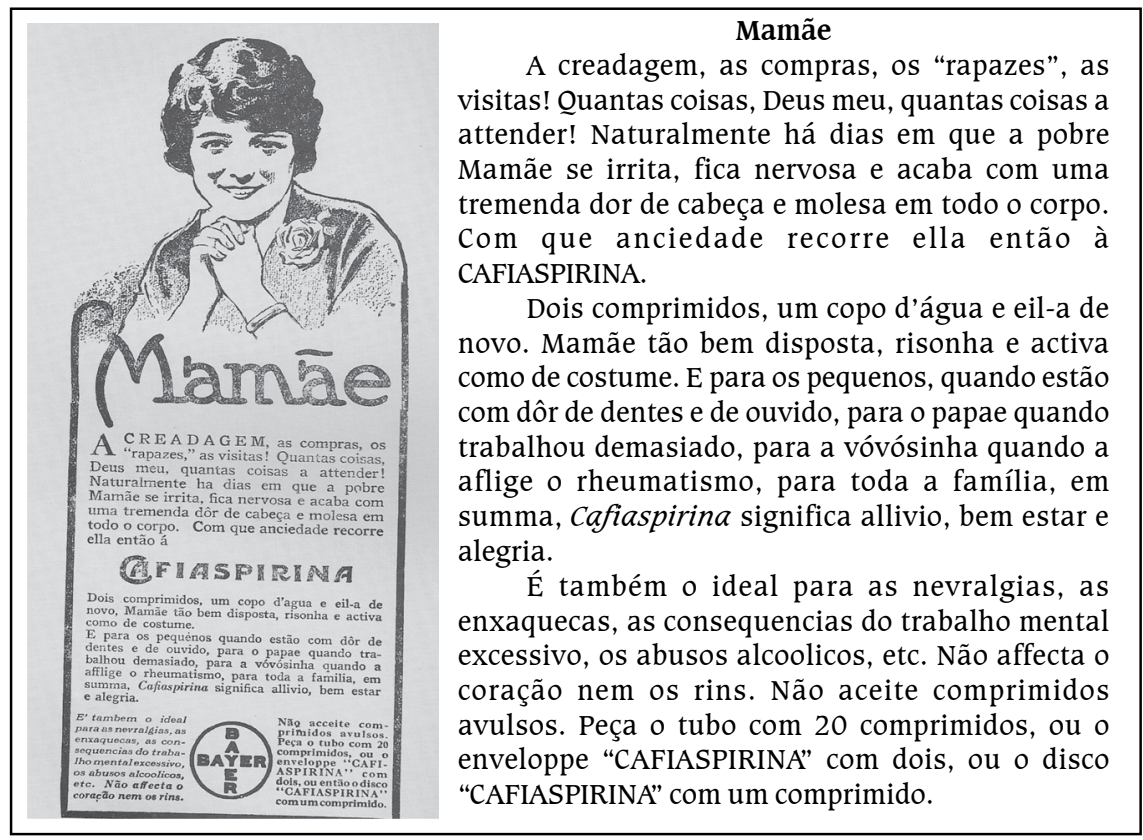

FIGURA 3 - RECLAMES DA BAYER 1911-1942 (p. 72).

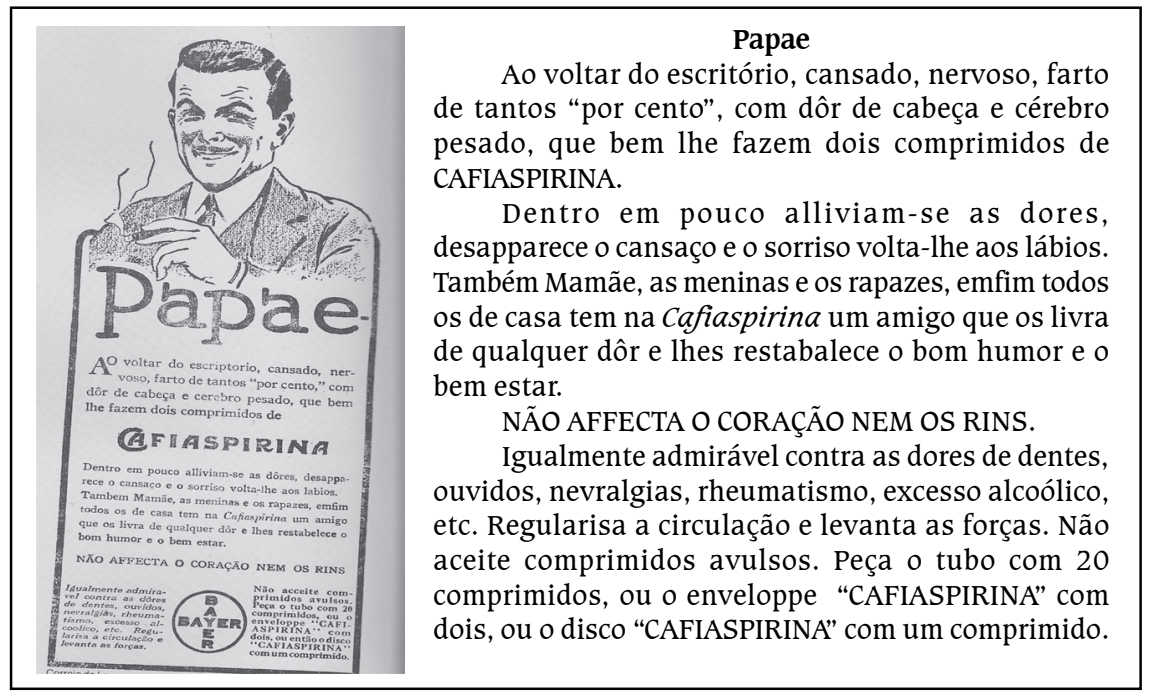

FIGURA 4 - RECLAMES DA BAYER 1911-1942 (p. 72). 
Esses últimos anúncios, que circularam no Correio da Lavoura (RJ) em setembro de 1926 (Figura 3) e agosto de 1926 (Figura 4), reverberam as representações observadas nos anteriores. Contudo, ao deixar bastante evidente os lugares sociais sedimentados de acordo com a desigualdade dos sexos, permitem-nos ainda notar que, tradicionalmente, tanto a figura do feminino quanto a do masculino está ligada às suas condições, às posições por eles ocupadas na sociedade. A mulher, por convenção e posição, está inevitavelmente voltada para a família, para o íntimo e, portanto, para o espaço privado. Já o homem ocupa o espaço público e está sujeito às relações mundanas. À mulher, a creadagem, as compras, "os rapazes", as visitas; ao homem, o escritório e os por cento. Ou seja, ao enunciar a mulher, a publicidade novamente reproduz os discursos que a confinam na esfera doméstica, lócus onde ela poderia (deveria) desempenhar com segurança seu papel de esposa, dona de casa, mãe e reprodutora; estas funções, vale lembrar, resumem seu pretenso destino o que faz com que muitas vezes ela seja identificada como santa, 'a que padece no paraíso', e é por isso que reiteradamente se afirma, inclusive na atualidade, que o papel da mulher é o de 'rainha do lar'. Ecoam desses discursos as vozes sociais que, ao reforçarem o lugar e as atribuições da esposa, reforçam a própria instituição do casamento.

A história da condição da mulher, enredada nesse anúncio, reitera os estereótipos globalizantes que são repassados de geração a geração: representada reiteradamente como mais fraca e mais frágil, a pobre mamãe estaria sempre dependendo da virilidade e da inteligência do chefe da casa. Também a maternidade, que sempre foi o emblema da mulher, engendra nesse discurso a imagem da abnegação e da dedicação, pois do bem estar da mamãe depende o bem estar de toda a família.

Os anúncios das Figuras 3 e 4, ao nosso ver, sedimentam o perfil burguês da mulher-dona-de-casa-mãe-de-família. Nas propagandas analisadas, essa mulher é, invariavelmente, representada como exemplo de honradez e de probidade; mantenedora de um sólido ambiente familiar e de um lar aconchegante. É, também, desobrigada de qualquer trabalho produtivo, pois a proteção material dos filhos e o sustento das despesas da casa é de responsabilidade exclusiva do pai (Figura 4), cabendo à mãe a tarefa de proteger as crianças e de prepará-las física, intelectual e moralmente para o convívio social (Figura 3).

Tomadas em seu conjunto, essas propagandas se inscrevem como verdadeiros guias de condutas, reforçando discursos que orientam seu público-alvo sobre como devem agir e pensar. São discursos que, além de explicar as características do produto anunciado, visam disciplinar os comportamentos, codificando os modos de vida, as aparências, os cuidados com a saúde. 


\title{
CONSIDERAÇÕES FiNAIS
}

As formações discursivas, no interior das quais apreendemos os discursos analisados, não apresentaram qualquer vestígio de um deslocamento dessas imagens para fora de suas zonas reservadas. Daí concluirmos que essas produções discursivas se configuram como uma importante prática discursiva que contribui para o delineamento dos contornos identitários das mulheres, em consonância com o momento sócio-histórico em que foram enunciadas.

Os antigos anúncios foram rememorados e reinterpretados dentro de uma ordem discursiva que deixa claro a ênfase dada sobre como deviam ser as relações sociais entre os homens e as mulheres nas primeiras décadas do século XX; enuncia 'verdades' e 'poderes' sobre os comportamentos de outrora; reitera vozes cristalizadas no imaginário social que afirmam, dentre outras questões, que a mulher é frágil, dócil, abnegada, e que os espaços/ posições ocupados por ela são estabelecidos de acordo com os sistemas de valores e de condutas daquela época.

\section{RESUMO}

O presente artigo tem como objetivo revisitar e rememorar antigos anúncios publicitários focalizando os modos de subjetivação do feminino em um momento sócio-histórico fortemente marcado pelos valores de nossa tradição patriarcal, em cujo cerne se visualiza uma hierarquia que fixou o masculino no topo e desenhou o feminino como um ser frágil e doente. Ancorados nos pressupostos teóricos da Análise do Discurso, de linha francesa, partimos do princípio de que a identidade do sujeito é uma construção histórica realizada pela linguagem e que a mídia é um lugar de enunciação que forja representações sociais.

Palavras-chave: anúncio publicitário; discurso; representação de gênero.

\begin{abstract}
This article aims at revisiting old advertisements focusing on a socio-historical moment marked by the values of our patriarchal tradition. In the core of this tradition it is possible to visualize that the hierarchy set the man on the top and
\end{abstract}


designed the woman as a fragile and an unfit being. Based on the theoretical propositions of French Discourse Analysis, it was taken into account the principle that the individual's identity is a historical construction realized by the language and that the media is where enunciation takes place and fakes the social representations.

Key-words: advertisements; discourse; genre representation.

\section{REFERÊNCIAS}

BOURDIEU, Pierre. A dominação masculina. Rio de Janeiro: Bertrand Brasil, 1999.

FOUCAULT, Michel. As palavras e as coisas: uma arqueologia das ciências humanas. 8. ed. São Paulo: Martins Fontes, 1999.

. Arqueologia do Saber. Rio de Janeiro: Forense Universitária, 1997.

GASTALDO, Edson. A representação do espaço doméstico e papéis de gênero na publicidade. In: FUNCK, Susana Bornéo; WIDHOLZER, Nara. Gênero em discursos da mídia. Florianópolis: Editora Mulheres / Edunisc, 2005. p. 53-59.

ORLANDI, Eni. Discurso fundador. Campinas: Pontes, 1993.

. Análise de Discurso. In: ORLANDI, Eni; LAGAZZI-RODRIGUES, Susy (Org.). Introdução às Ciências da Linguagem: Discurso e textualidade. Campinas: Pontes, 2006. p. 33-80.

PÊCHEUX, Michel. Semântica e discurso: uma crítica à afirmação do óbvio. Campinas: Unicamp, 1995.

PÊCHEUX, Michel; FUCHS, Catherine. A propósito da Análise Automática do Discurso: Atualização e perspectivas. In: GADET, F.; HAK, T. (Org.). Por uma análise automática do discurso. Uma introdução à Obra de Michel Pêcheux. Campinas: Unicamp, 1997.

PERROT, Michelle. As mulheres ou os silêncios da história. Bauru-SP: Edusc, 2005. . Minha história das mulheres. São Paulo: Contexto, 2007.

RECLAMES DA BAYER 1911-1942. Bayer do Brasil S.A. Área de Comunicação e Propaganda, 1986.

SCOTT, Joan. Gênero: uma categoria útil de análise histórica. Educação e Realidade, Porto Alegre, v. 20, n. 2, p. 71-99, jul./dez. 1995.

Submetido em: 22/11/2007.

Aceito em: 08/10/2008. 